\title{
A Novel Insight into the Cardiotoxicity of Antineoplastic Drug Doxorubicin
}

\section{Zbynek Heger ${ }^{1}$, Natalia Cernei ${ }^{1,2}$, Jiri Kudr ${ }^{1}$, Jaromir Gumulec ${ }^{1,2,3}$, Iva Blazkova ${ }^{1}$, Ondrej Zitka ${ }^{1,2}$, Tomas Eckschlager ${ }^{4}$, Marie Stiborova ${ }^{5}$, Vojtech Adam ${ }^{1,2}$ and Rene Kizek ${ }^{1,2, *}$}

1 Department of Chemistry and Biochemistry, Faculty of Agronomy, Mendel University in Brno, Zemedelska 1, Brno CZ-613 00, Czech Republic, E-Mails: heger@mendelu.cz (Z.H.); cernei.natalia3@gmail.com (N.C.); george.kudr@centrum.cz (J.K.); j.gumulec@gmail.com (J.G.); iva.blazkova@seznam.cz (I.B.); ZitkaO@seznam.cz (O.Z.); vojtech.adam@mendelu.cz (V.A.)

2 Central European Institute of Technology, Brno University of Technology, Technicka 3058/10, Brno CZ-616 00, Czech Republic

3 Department of Pathological Physiology, Faculty of Medicine, Masaryk University, Komenskeho namesti 2, Brno CZ-662 43, Czech Republic

4 Department of Paediatric Haematology and Oncology, 2nd Faculty of Medicine, Charles University, and University Hospital Motol, V Uvalu 84, Prague 5 CZ-15006, Czech Republic; E-Mail: Tomas.Eckschlager@fnmotol.cz

5 Department of Biochemistry, Faculty of Science, Charles University, Albertov 2030, Prague 2 CZ-12840, Czech Republic; E-Mail: stiborov@natur.cuni.cz

* Author to whom correspondence should be addressed; E-Mail: kizek@sci.muni.cz; Tel.: +420-545-133-350; Fax: +420-545-212-044.

Received: 29 August 2013; in revised form: 26 September 2013 / Accepted: 9 October 2013 / Published: 31 October 2013

Abstract: Doxorubicin is a commonly used antineoplastic agent in the treatment of many types of cancer. Little is known about the interactions of doxorubicin with cardiac biomolecules. Serious cardiotoxicity including dilated cardiomyopathy often resulting in a fatal congestive heart failure may occur as a consequence of chemotherapy with doxorubicin. The purpose of this study was to determine the effect of exposure to doxorubicin on the changes in major amino acids in tissue of cardiac muscle (proline, taurine, glutamic acid, arginine, aspartic acid, leucine, glycine, valine, alanine, isoleucine, threonine, lysine and serine). An in vitro interaction study was performed as a comparison of amino acid profiles in heart tissue before and after application of doxorubicin. We found that doxorubicin directly influences myocardial amino acid representation even at low 
concentrations. In addition, we performed an interaction study that resulted in the determination of breaking points for each of analyzed amino acids. Lysine, arginine, $\beta$-alanine, valine and serine were determined as the most sensitive amino acids. Additionally we compared amino acid profiles of myocardium before and after exposure to doxorubicin. The amount of amino acids after interaction with doxorubicin was significantly reduced $(p=0.05)$. This fact points at an ability of doxorubicin to induce changes in quantitative composition of amino acids in myocardium. Moreover, this confirms that the interactions between doxorubicin and amino acids may act as another factor most likely responsible for adverse effects of doxorubicin on myocardium.

Keywords: myocardium; cardiomyopathy; interaction; amide bond; spectrophotometry; ion-exchange liquid chromatography

Abbreviations: 4E-BP, 4E-binding protein; AA, Amino acids; BCAAs, Branched-chain amino acids; DNR, Daunorubicin; DOX, Doxorubicin; IELC, Ion-exchange liquid chromatography; mPTPs, Mitochondrial permeability transition pores; mTOR, Mammalian target of rapamycin; ROS, Reactive oxygen species; S6K, S6 kinase; SREBP, Sterol response element binding protein.

\section{Introduction}

Doxorubicin, an anthracycline antibiotic, is widely used to treat a number of cancers [1-3], including as breast and lung cancers [4-6]. The first anthracyclines were isolated from the pigment-producing Streptomyces peucetius var. caesius in the 1960s and named doxorubicin (DOX) and daunorubicin (DNR) [7]. They still remain one of the most effective chemotherapeutic antitumor agents [8], which effect is based on intercalation into DNA helix [9]. In addition, they inhibit the activity of enzyme topoisomerase II that prevents DNA repairing [10-12]. Doxorubicin (DOX) also acts by stabilizing a reaction, in which DNA strands are cut and covalently connected to the tyrosine residues of topoisomerase II, eventually impeding DNA resealing. Topoisomerase II-induced DNA damage is followed by a growth arrest in the $G_{1}$ and $G_{2}$ phases and apoptosis [13]. Anthracyclines exert their cytotoxic effect also by generating reactive oxygen species (ROS) [14], such as $\mathrm{H}_{2} \mathrm{O}_{2}$ and superoxide anion radical [15]. These pro-oxidant properties of DOX have a potential to induce cell death through an oxidative damage of mitochondria [16].

On the other hand, doxorubicin may cause several side effects $[17,18]$, which are mainly evidenced by serious deteriorations of the cardiac muscle including dilated cardiomyopathy [19-21], congestive heart failure [22,23], arrhythmias [24] and also myelotoxicity [7]. All these effects significantly limit clinical use of DOX. Despite the extensive studies of the cardiotoxicity of DOX at cellular, biochemical, molecular, and genetic levels, it has not satisfactorily been elucidated yet [7,11]. Most likely, it is a multifactorial process where alterations in cellular structure [25], formation of ROS that attack the non-target structures [26,27], and induction of apoptosis [20,28] play the important roles. Therefore, new strategies for decreasing the cardiotoxicity of DOX are looking for. 
Amino acids exert a cardioprotective effect in ischemia and other cardiac disorders. They play a crucial role in the cardiac metabolism as a source of acetyl-CoA, and contribute to the production of $\mathrm{NADH}$ and $\mathrm{FADH}_{2}$ and conversion of glutamine and glutamate to free radical scavengers $[29,30]$. However, the relevance of amino acid metabolism in the general population suffering from heart diseases remains still poorly elucidated [31].

The in vitro ion-exchange liquid chromatographic (IELC) and spectrophotometric studies of interactions between fundamental amino acids contained in myocardium with major representative of the anthracycline cytostatics doxorubicin and comparison of content and representation of amino acids in myocardium before and after exposure to doxorubicin were the most important aims of this study. We also determined the breaking points, the critical amount of DOX that is sufficient for formation of mutual complexes for each amino acid.

\section{Results and Discussion}

\subsection{Amino Acid Profile of Chicken Myocardium}

The purpose of the study was to investigate the influence of DOX on major amino acids present in myocardium. Proline, taurine, glutamic acid, arginine, aspartic acid, leucine, glycine, valine, alanine, isoleucine, threonine, lysine and serine in the downward trend were determined as the most common amino acids in the amino acid profile obtained by IELC. Their concentrations ranged from $1 \mu \mathrm{mol} \mathrm{mL} L^{-1}$ for serine to $14 \mu \mathrm{mol} \mathrm{mL}{ }^{-1}$ for proline (Figure 1), where values of concentrations were obtained as the averages from ten independent measurements. These values ranged in amounts similar to values of some amino acids that were determined in human heart in the study by Weitzel et al. [32]. All these amino acids were subsequently used for monitoring possible interactions with DOX.

Figure 1. Average content of amino acids in chicken hearts (average of measurements of 10 samples). Measurements were carried out using ion-exchange liquid chromatography (IELC) with postcolumn derivatization with ninhydrin.

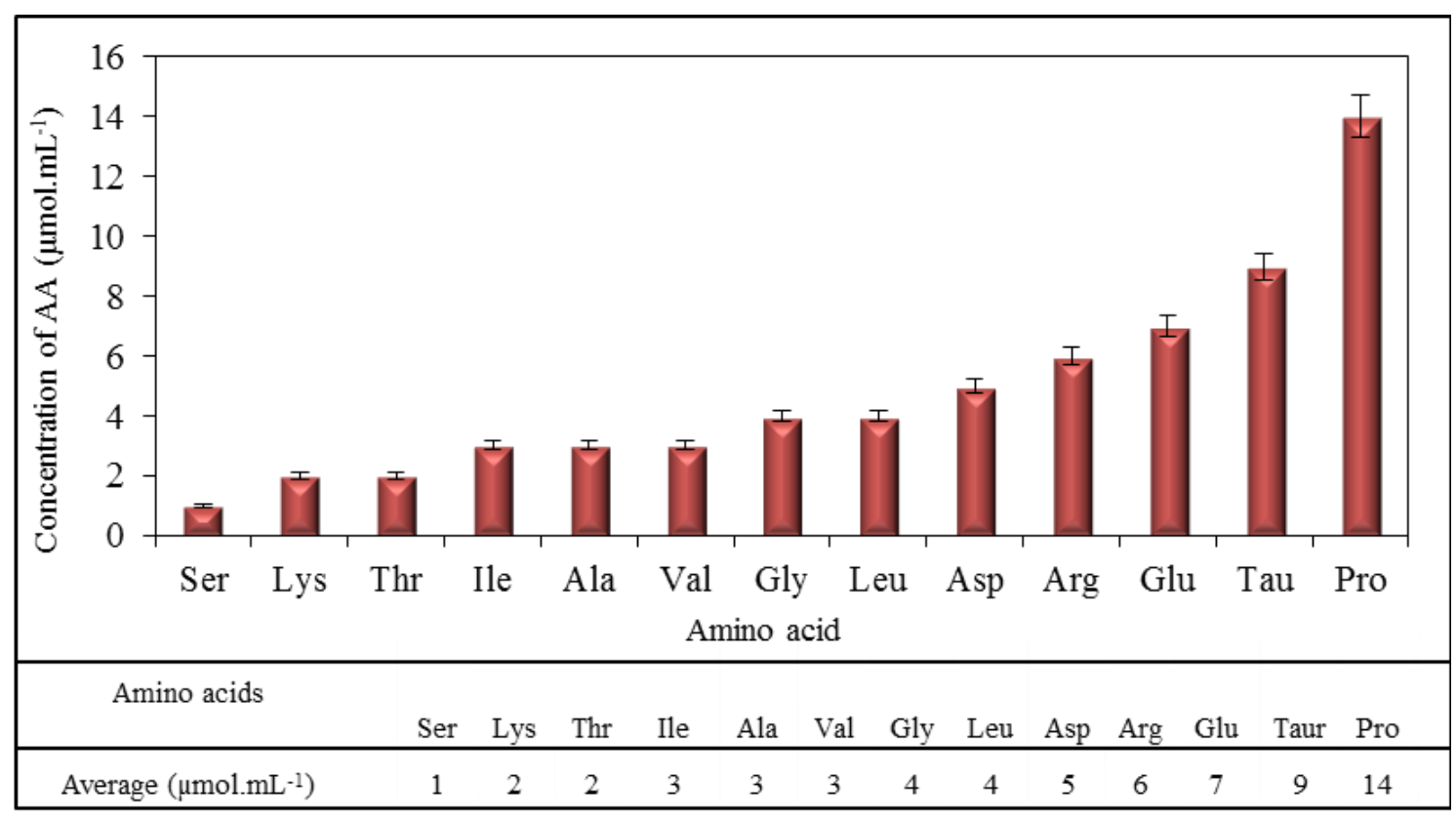




\subsection{Spectrophotometric Analysis of Amino Acids-Doxorubicin Interactions}

To investigate DOX-induced interactions with amino acids, we primarily used an UV-VIS spectrophotometric method. Marked interactions of lysine, $\beta$-alanine, valine, and arginine respectively were evident from the obtained spectra. The spectra of interactions of DOX with other amino acids pointed at no interactions at the constant concentration of doxorubicin when compared different concentrations of AA (Figures 2 and 3). Doxorubicin exhibited the maximum at $\lambda=480 \mathrm{~nm}$, which corresponds to findings published in several studies [33-35]. Lysine (Figure 2A), whose amino group is highly reactive and often participates in enzymatic reactions [29], $\beta$-alanine (Figure 2E), serine (Figure 3G), valine (Figure 3I) and arginine (Figure 3M) showed significantly stronger interaction with DOX with the increasing concentration (in a concentration dependent manner; highest effects observed at the concentration of $1000 \mu \mathrm{g} \mathrm{mL}{ }^{-1}$ ) and thus indicated the highest binding affinity for the formation of complex with DOX. This phenomenon was monitored up to the concentration of $3 \mu \mathrm{mol} \mathrm{mL}{ }^{-1}$ (serine), and $12 \mu \mathrm{mol} \mathrm{mL} \mathrm{m}^{-1}$ (lysine, arginine, $\beta$-alanine, valine and aspartic acid). Other amino acids showed interactions with DOX in much higher concentrations applied as it is apparent from doxorubicin peaks. Trends confirming the above mentioned facts can be seen in insets (a) in Figures 2 and 3, which indicate relations between the concentration of amino acid interacting with DOX and its subsequent effect on absorbance of DOX. Decreasing trend in the series serine, lysine, $\beta$-alanine, valine, and arginine points at higher interaction rates and at a higher content of individual amino acids. The insert curves showed no significant changes in the case of all other amino acids.

In addition, we also processed differential spectra of DOX-AA interactions. These results show real forms of interaction output and its real wavelength (insets (a) in Figures 2 and 3). When doxorubicin subjected to interaction with serine, lysine, arginine, $\beta$-alanine, valine and aspartic acid, shifts of maximum wavelengths within the range from 464 to $465 \mathrm{~nm}$ were observed. Similar wavelength shift was observed also in the case of proline that changed wavelength of doxorubicin to $\lambda=462 \mathrm{~nm}$. Other amino acids exhibited relatively small shifts of DOX wavelength, but the differences were present at all of them. These changes mention the amendment to structural changes of molecule of DOX, which is capable to form a complex with amino acid. Curves in insets (a) in Figures 2 and 3 point at weak interaction between DOX, proline and glycine. This interaction is not influenced by concentrations of these amino acids. Low effects of AA concentrations were also observed in the case of leucine, isoleucine, and threonine. Interestingly, among these amino acids the smallest wavelength changes of doxorubicin were also observed. These amino acids were shown as the least accessible for the interaction with DOX. Using the spectrophotometric method we proved that doxorubicin may interact with some amino acids, the basic stones of all myocardial proteins, substrates for the synthesis of proteins, and products of their degradation. Some connections with these products were also found by Taetrneyer et al. [36]. 
Figure 2. Interactions of amino acids $\left(1 ; 2 ; 3 ; 6 ; 12 ; 25 ; 50 ; 100 \mu \mathrm{mol} \mathrm{mL}{ }^{-1}\right)$ with doxorubicin $\left(100 \mu \mathrm{g} \mathrm{mL}^{-1}\right)$ monitored with spectrophotometry. DOX interaction with: (A) lysine; (B) proline; (C) glycine; (D) taurine; (E) $\beta$-alanine, (F) threonine; where (a) stays for $100 \mu \mathrm{mol} \mathrm{mL} L^{-1}$; (b) $50 \mu \mathrm{mol} \mathrm{mL}{ }^{-1}$; (c) $25 \mu \mathrm{mol} \mathrm{mL} L^{-1}$; (d) $12 \mu \mathrm{mol} \mathrm{mL} \mathrm{mL}^{-1}$; (e) $6 \mu \mathrm{mol} \mathrm{mL} L^{-1}$; (f) $3 \mu \mathrm{mol} \mathrm{mL} L^{-1}$; (g) $2 \mu \mathrm{mol} \mathrm{mL} L^{-1}$; (h) $1 \mu \mathrm{mol} \mathrm{mL}^{-1}$; (i) $0 \mu \mathrm{mol} \mathrm{mL} \mathrm{m}^{-1}$ and (j) for control (AA without DOX). The dependence of the DOX absorbance at $480 \mathrm{~nm}$ on the different concentrations of amino acids is shown in insets marked with lowercase letter a. Insets marked with lowercase letter $b$ express the differences obtained from differential spectra gained as a readout of DOX spectrum from DOX-AA complex spectrum with observed wavelength maximum changes.

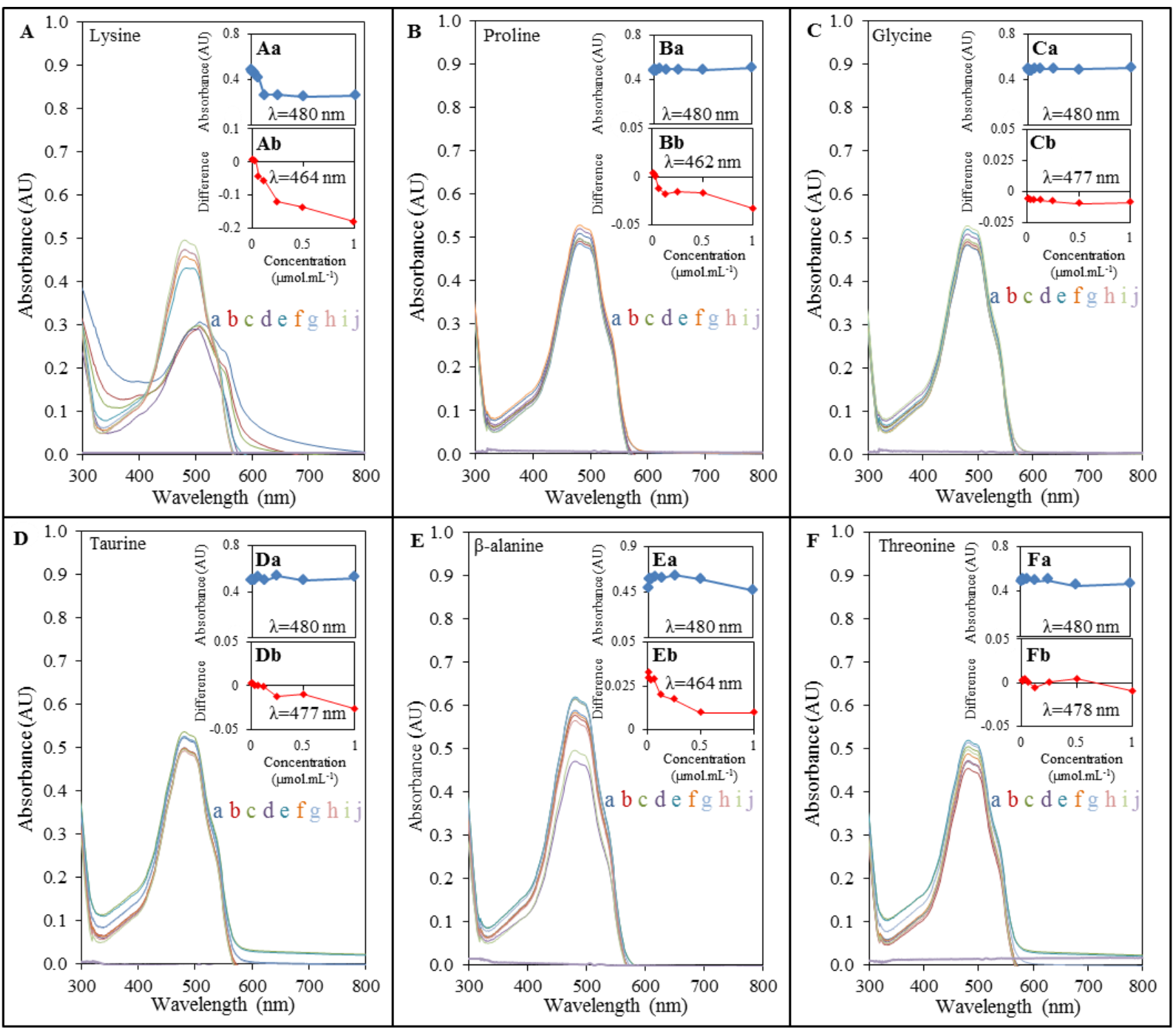


Figure 3. Interactions of amino acids $\left(1 ; 2 ; 3 ; 6 ; 12 ; 25 ; 50 ; 100 \mu \mathrm{mol} \mathrm{mL}^{-1}\right)$ with doxorubicin $\left(100 \mu \mathrm{g} \mathrm{mL}^{-1}\right)$ monitored with spectrophotometry. DOX interaction with: (G) serine; (H) aspartic acid; (I) valine; (J) glutamic acid; (K) isoleucine; (L) leucine; (M) arginine, where (a) stays for $100 \mu \mathrm{mol} \mathrm{mL} L^{-1}$; (b) for $50 \mu \mathrm{mol} \mathrm{mL}^{-1}$; (c) $25 \mu \mathrm{mol} \mathrm{mL}^{-1}$; (d) $12 \mu \mathrm{mol} \mathrm{mL} \mathrm{m}^{-1}$; (e) $6 \mu \mathrm{mol} \mathrm{mL} L^{-1}$; (f) $3 \mu \mathrm{mol} \mathrm{mL}{ }^{-1}$; (g) $2 \mu \mathrm{mol} \mathrm{mL}^{-1}$; (h) $1 \mu \mathrm{mol} \mathrm{mL}{ }^{-1}$; (i) $0 \mu \mathrm{mol} \mathrm{mL} \mathrm{m}^{-1}$ and (j) for control (AA without DOX). The dependence of the absorbance at $480 \mathrm{~nm}$ on the different concentrations of amino acids can be observed in insets marked with lowercase letter a. Insets marked with lowercase letter $b$ express the differences obtained from differential spectra gained as readout of DOX spectrum from DOX-AA complex spectrum with observed wavelength changes.

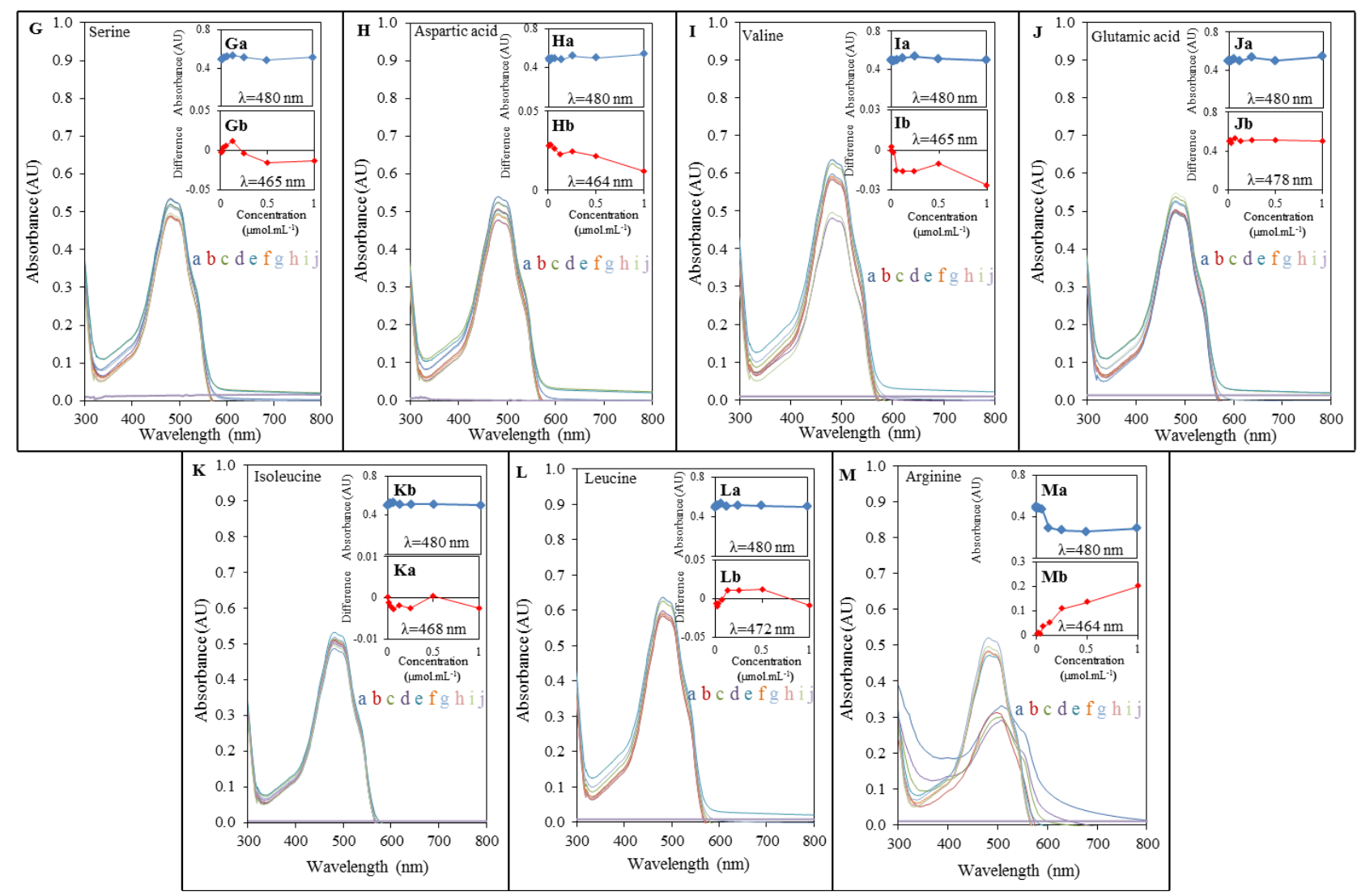

\subsection{Analysis of Amino Acids-Doxorubicin Interactions by IELC}

To gain more detailed insight into the mechanisms, in terms of how doxorubicin interacts with the amino acids, we carried out IELC analysis. For this purpose, different concentrations of DOX were subjected to interaction with the constant concentration of each AA. As illustrated in Figures 4 and 5, we similarly observed apparent effect of DOX on amino acids serine, lysine, $\beta$-alanine, valine, and arginine respectively. Surprisingly, we also observed its effect on other amino acids, i.e., proline, glycine, taurine, threonine, aspartic acid, glutamic acid, isoleucine, and leucine. This effect was manifested even at relatively low concentrations of doxorubicin in the range between $1 \mu \mathrm{mol} \mathrm{mL} \mathrm{m}^{-1}$ for serine and $84 \mu \mathrm{mol} \mathrm{mL}{ }^{-1}$ for glutamic acid (see Chapter Breaking points of amino acids). Amino acids may act as important signaling molecules [31], especially BCAAs are effective activators of the mammalian target of rapamycin (mTOR) signalling cascade [37], which is directly involved in cardiac 
hypertrophy in pathways of regulation of proteosynthesis [38,39]. The main function of mTOR is the stimulation of cell growth and anabolism through increasing protein and lipid synthesis via activation of S6K (S6 kinase), 4E-BP (4E-binding protein), and SREBP (sterol response element binding protein) $[40,41]$. The limited availability of myocardial proteins and the potential to lose the function may induce structural alterations resulting in the formation of free radicals or in changes in antioxidant status [42-44]. Accumulation of free radicals may play a crucial role in depletion of adenosine triphosphate and subsequent opening of the non-specific mitochondrial permeability transition pores (mPTPs) [45] allowing molecules smaller than $1.5 \mathrm{kDa}$ to penetrate through the mitochondrial pores and change mitochondrial membrane potential. All these effects, especially the loss of mitochondrial membrane potential, leads to the release of molecules with pro-apoptotic potential (e.g., cytochrome c) into cytosol [46,47], which results in the degradation of mitochondria, loss of myofilaments and progressive atrophy of myofibrils [48].

Figure 4. Interaction of amino acids $\left(100 \mu \mathrm{mol} \mathrm{mL} \mathrm{m}^{-1}\right)$ with doxorubicin $(8 ; 16 ; 32 ; 64$; 125; 250; 500; $1000 \mu \mathrm{g} \mathrm{mL}^{-1}$ ) monitored with IELC. DOX interaction with: (A) lysine; (B) proline; (C) glycine; (D) taurine; (E) $\beta$-alanine; (F) threonine. $\boldsymbol{\Delta}$ Expression of retention time changes $(\mathrm{min}) ; \times$ real curve of a sample and - calculated overlay expressing amino acids breaking points.

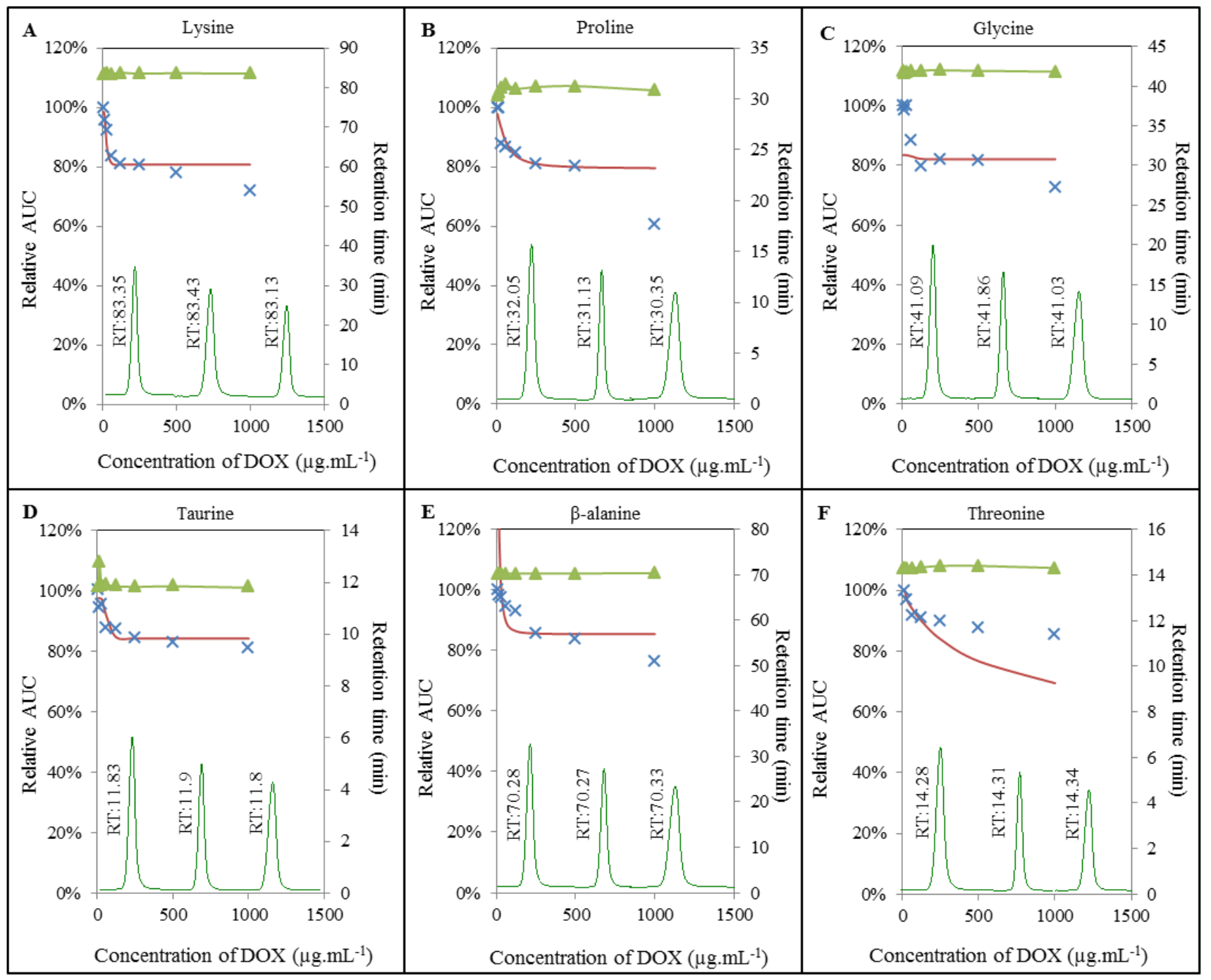


Figure 5. Interaction of amino acids $\left(100 \mu \mathrm{mol} \mathrm{mL} \mathrm{mL}^{-1}\right)$ with doxorubicin $(8 ; 16 ; 32 ; 62$; 125; 250; 500; $\left.1000 \mu \mathrm{g} \mathrm{mL}{ }^{-1}\right)$ monitored with IELC. DOX interaction with: $(\mathbf{J})$ serine; $(\mathbf{K})$ aspartic acid; $(\mathbf{L})$ valine; $(\mathbf{M})$ glutamic acid; $(\mathbf{N})$ isoleucine; $(\mathbf{O})$ leucine; $(\mathbf{P})$ arginine. $\Delta$ Expression of retention time changes $(\mathrm{min}) ; \times$ real curve of a sample and-calculated overlay expressing amino acids breaking points.

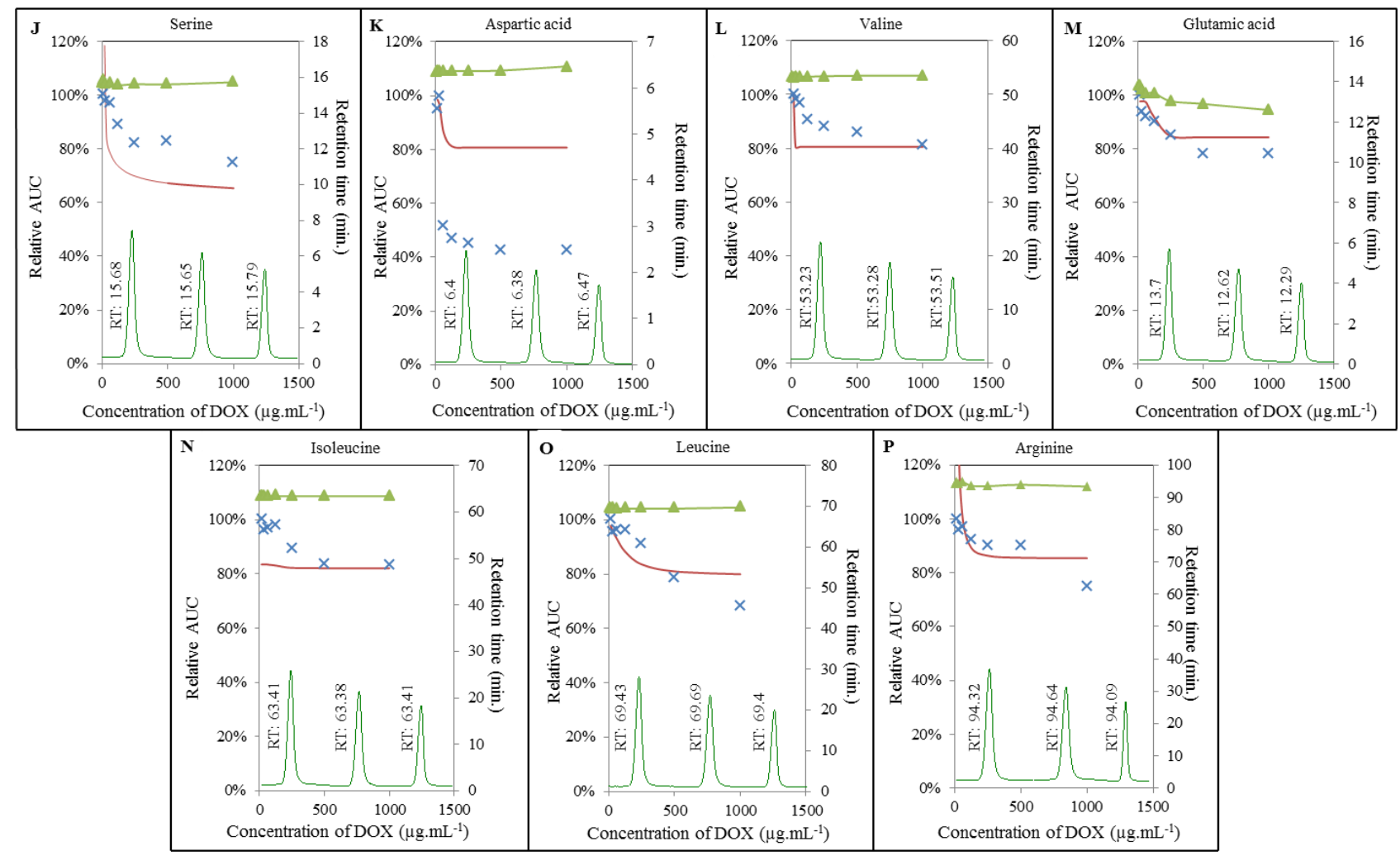

Additionally, we also investigated retention times of individual amino acids. Whereas most of the amino acids analyzed maintained their retention time under the influence of doxorubicin without significant changes, retention time of proline was significantly influenced by DOX in the concentration-dependent manner (Figure 4B). Retention time of proline without DOX added was established at $32.05 \mathrm{~min}$. The highest concentration of doxorubicin $\left(1000 \mu \mathrm{g} \mathrm{mL}{ }^{-1}\right)$ led to a shortening of retention time to $30.35 \mathrm{~min}$. Similar changes in retention time were observed in the case of glutamic acid, where the signal was observed after 13.7 min without DOX and after 12.29 min after adding of $1000 \mu \mathrm{g} \mathrm{mL}^{-1}$ of doxorubicin (Figure $5 \mathrm{M}$ ). Changes in retention time point at a possible formation of certain AA-DOX complex that has very similar properties as corresponding amino acid, but slightly shifted its retention time.

\subsection{Effect of Doxorubicin on Breaking Points of Amino Acids}

Results of IELC analysis showed that doxorubicin interacts with amino acids, especially at low concentrations. Due to this fact, we carried out mathematical analysis of the breaking points for individual amino acids to determine the lowest concentration of DOX that causes noticeable effect on AA (Figure 6A), expressed as the lowest concentration of DOX required for formation of the complex with AA. The lowest breaking point has been determined for serine at the concentration of $1 \mu \mathrm{g} \mathrm{mL}^{-1}$ 
of doxorubicin. The highest one has been shown for glutamic acid $\left(84 \mu \mathrm{g} \mathrm{mL} \mathrm{m}^{-1}\right)$. The breaking points of all analyzed amino acids are shown in Table 1. As it is clear from Table 1, doxorubicin possesses the ability to interact with amino acids in concentrations lower than we expected. Predictive value of breaking points according to cardiotoxicity is considerable, but it is important to reveal the real amino acids composition of heart. This information may be further applied as a simple mathematical calculation revealing how much of doxorubicin has potential to influence the major amino acids - especially the most vulnerable ones. When compared with spectrophotometric analysis, serine showed the lowest breaking point, however, amino acids serine, lysine, arginine, $\beta$-alanine, and valine have very low values of breaking point; thus, these amino acids are the most accessible for interaction with DOX. Valine belongs to the important group of BCAAs that act as the activators of mTOR signalling pathway [49,50]. The depletion of these amino acids may result in the alterations in the function of mTOR with subsequent influencing of synthesis of proteins.

Figure 6. (A) Expression of DOX influence on amino acids via breaking points representing the lowest concentration of DOX showing a noticeable effect on amino acids. Results were obtained using IELC with postcolumn derivatization; (B) Expression of the effect of amino acids concentrations on DOX spectra carried out on UV/VIS spectrophotometry. There are shown amino acids concentrations, at which DOX spectra showed first observable differences.

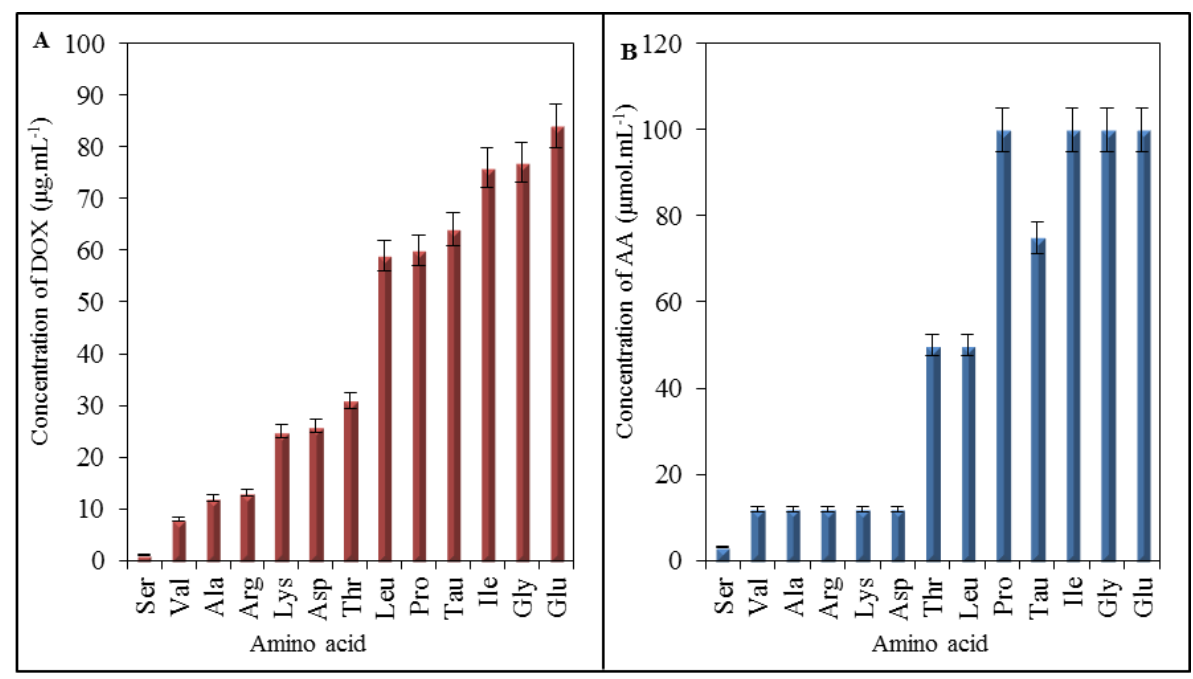

In addition, we assembled the summarizing output from UV/VIS spectrophotometric analysis (Figure 6B). These results are similar to the breaking points shown in Figure 6A regarding to a willingness of amino acids to interact (form a complex) with DOX. When comparing these two outputs coming from different analyses, in the case of the amino acids, which are influenced by the lowest DOX concentration simultaneously, it is valid that a low concentration of amino acid is sufficient to be influenced by the constant concentration of DOX. Serine at the concentration of $3 \mu \mathrm{mol} \mathrm{mL} \mathrm{m}^{-1}$ exhibited noticeable effect of DOX. At valine, lysine, arginine, $\beta$-alanine and aspartic acid sufficient concentration for the same effect was detected to $12 \mu \mathrm{mol} \mathrm{mL} \mathrm{m}^{-1}$. Threonine and leucine were influenced by DOX at the concentrations of $50 \mu \mathrm{mol} \mathrm{mL}{ }^{-1}$, taurine at $75 \mu \mathrm{mol} \mathrm{mL}{ }^{-1}$ and proline, glycine, isoleucine and glutamic acid at $100 \mu \mathrm{mol} \mathrm{mL} \mathrm{m}^{-1}$. The concentrations are indicative 
for verifying of the interaction trends and are based on the initial concentrations used for UV/VIS spectrophotometric analysis.

Table 1. Overview of the breaking points expressing the lowest concentration of doxorubicin that influences noticeably the amino acids analysed. Ser — serine, Val—valine, Ala — $\beta$-alanine, Lys - lysine, Asp — aspartic acid, Thr - threonine, Leu-leucine, Pro-proline, Tau - taurine, Ile — isoleucine, Gly—glycine, Glu—glutamic acid, BP—breaking point.

\begin{tabular}{cccccccccccccc}
\hline Amino acid & Ser & Val & Ala & Arg & Lys & Asp & Thr & Leu & Pro & Tau & Ile & Gly & Glu \\
\hline $\mathrm{BP}\left(\mu \mathrm{g} \mathrm{mL}^{-1}\right.$ of $\left.\mathrm{DOX}\right)$ & 1 & 8 & 12 & 13 & 25 & 26 & 31 & 59 & 60 & 64 & 76 & 77 & 84 \\
\hline
\end{tabular}

\subsection{Impact of Doxorubicin on Amino Acids}

According to Manocha and Margaritis, and Yoo and Park [35,51], DOX is a positively charged amphoteric molecule, containing in its sugar moiety (daunosamine) a protonable amino group and in its aglycone part, two deprotonable phenolic groups (Figure 7). At physiological pH or in deionized distilled water, the amino group gets protonated $\left(\right.$ as $\mathrm{NH}_{3}{ }^{+}$) and provides positive charge to the DOX molecule [35]. Hence, it is most likely that electrostatic interactions are established between positively charged DOX and negatively charged amino acids, which results in formation of the DOX-AA complexes in dependence on binding affinity of AA. The ability of doxorubicin to form a linkage through the amide bond has been already described in several studies [52-54]. Therefore, we hypothesize that DOX-AA complexes are formed in the physiological environment found in the human body and this fact affects non-target cytotoxicity of doxorubicin.

Figure 7. Scheme of the interaction between amino acid and doxorubicin resulting in a complex formation, where * stands for protonable functional group; ** stands for deprotonable group.

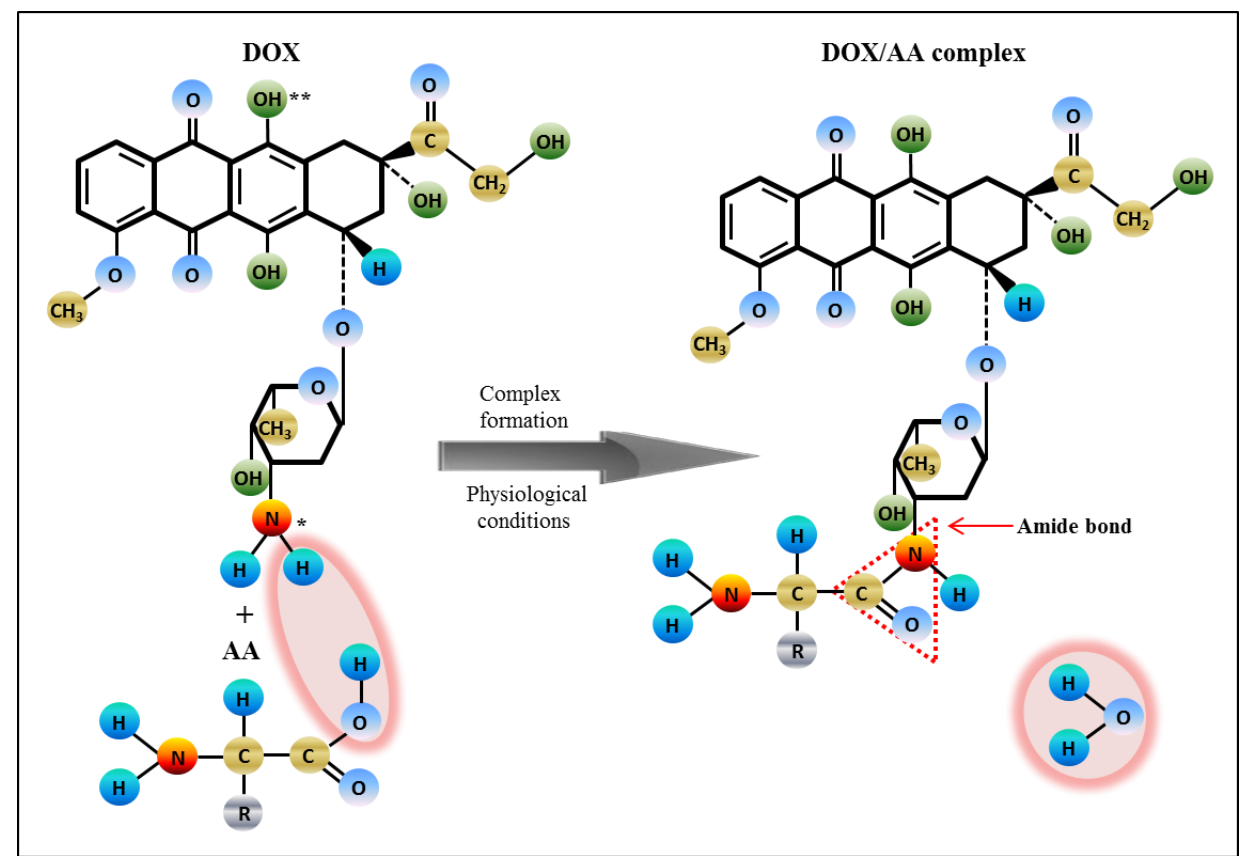




\subsection{Comparison of Amino Acid Profile of Myocardium before and after Application of Doxorubicin}

We carried out scans of both hearts, untreated and treated with DOX, to confirm its presence in myocardium (Figure 8A,B). Distribution of DOX (red highlighting) mainly in heart apex and estuary of aorta is well evident (red highlighting) in Figure 8B. Compared with control, reduced levels of amino acids occurring in myocardium after exposure to doxorubicin were observed. Proline (19.94\% disparity), taurine (19.03\%), and glutamic acid (32.54\%) were the least affected amino acids by DOX. On the other hand, serine $(85.18 \%)$ and lysine $(83.16 \%)$ followed by valine $(78.51 \%)$ and $\beta$-alanine (77.02\%) were the most affected amino acids in myocardium (Figure 8C). These data support our findings from previous measurements about increased reactivity of above mentioned amino acids and their ability to interact easily with doxorubicin.

Figure 8. Comparison of chicken myocardium before and after application of $1000 \mu \mathrm{g} \mathrm{mL}^{-1}$ of doxorubicin dissolved in physiological saline solution. (A) Chicken cardiac muscle tissue without doxorubicin applied (X-ray image with overlaid fluorescence image); (B) Chicken cardiac muscle tissue with $50 \mu \mathrm{L}$ of doxorubicin applied (X-ray image with overlaid fluorescence image). The fluorescence of doxorubicin was detected by Carestream In Vivo Xtreme Imaging System; (C) Expression of IELC results of myocardium amino acids content analysis. Both, control and heart, after application of doxorubicin were obtained as the averages from ten measurements. In inset it can be seen the percentage expression of differences between AA concentrations of amino acids in myocardium between and after application of DOX. * refer the differences between amino acid contents as statistically significant (at the $p=0.05$ level).

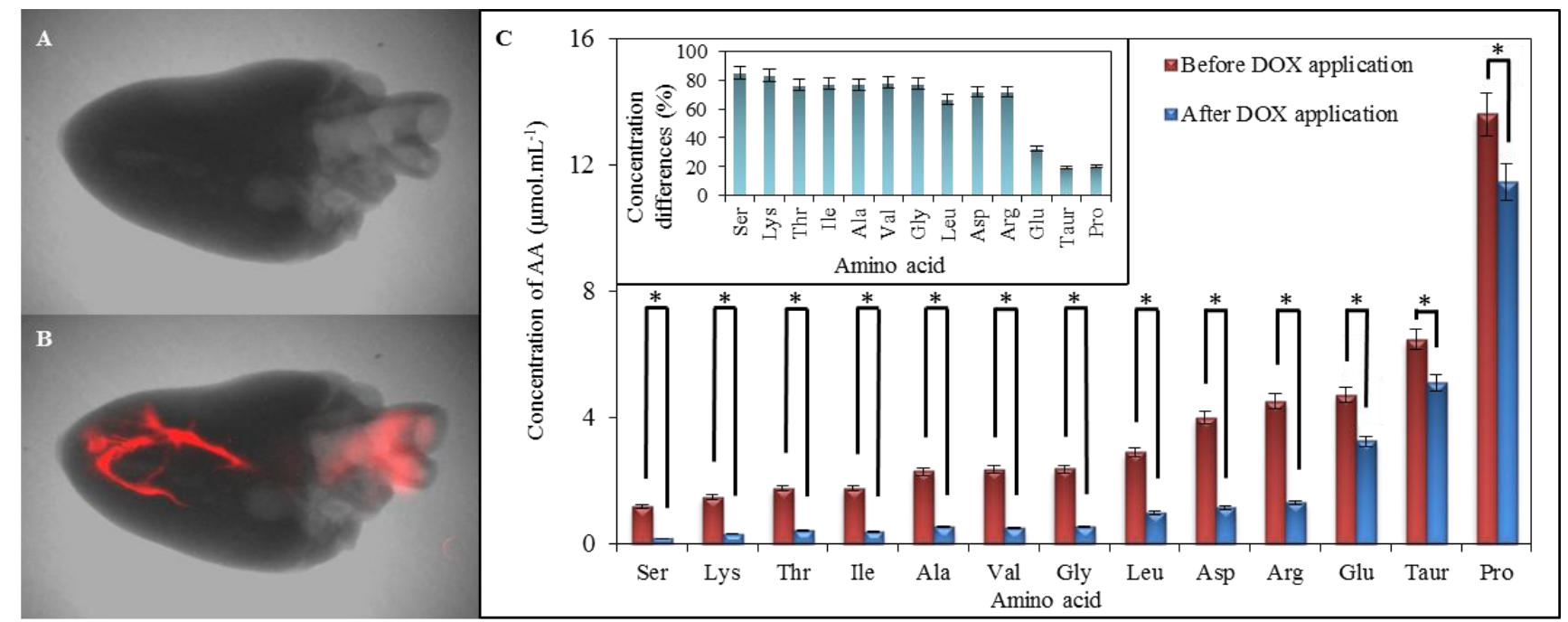

\section{Experimental Section}

\subsection{Chemicals and pH Measurement}

Working solutions as buffers or standard solutions of amino acids and DOX were prepared daily by a diluting the stock solutions. Amino acids, DOX standards and others were purchased from Sigma Aldrich (St. Louis, MO, USA) in ACS purity, unless noted otherwise. All solutions were prepared in 
deionized water obtained using a reverse osmosis equipment Aqual 25 (Aqual s.r.o., Brno, Czech Republic). The deionized water was further purified by using an apparatus Direct-Q 3 UV Water Purification System equipped with an UV lamp from Millipore (Billerica, MA, USA). The resistance was established to $18 \mathrm{M} \Omega \mathrm{cm}^{-1}$. The $\mathrm{pH}$ was measured using a $\mathrm{pH}$ meter WTW inoLab (Weilheim, Germany).

\subsection{Preparation of Myocardium Samples and DOX Fluorescence Detection}

For acquisition of the profiles of amino acids, ten chicken hearts were obtained (Diema s.r.o., Frydek-Mistek, Czech Republic). From each heart ( $n=10), 10 \mathrm{mg}$ of tissue was equally removed, weighed and added to $0.5 \mathrm{~mL}$ of $6 \mathrm{M} \mathrm{HCl}$. Sample was subsequently subjected to digestion in a microwave reaction system Anton Paar (Anton Paar GmbH, Graz, Austria) using the following conditions: power-80, Ramp $15 \mathrm{~min}$, Hold $90 \mathrm{~min}$, Max $120{ }^{\circ} \mathrm{C}$, Max pressure 25 bar, Rotor-XF-100-6. Thereafter, the digested sample was diluted 10 times with dilution buffer composed of thiodiglycol $5 \mathrm{~mL} \mathrm{~L}^{-1}$, citric acid $14 \mathrm{~g} \mathrm{~L}^{-1}$, sodium chloride $11.5 \mathrm{~g} \mathrm{~mL}^{-1}$ and centrifuged using a Microcentrifuge 5417R (Eppendorf AG, Hamburg, Germany) under 25,000 g at $4{ }^{\circ} \mathrm{C}$ for $10 \mathrm{~min}$. The samples prepared like this were diluted with a neutralizing solution ( $6 \mathrm{M} \mathrm{NaOH}$ in a dilution buffer) again in ratio 1:1 and analyzed on an analyzer of amino acids (Model AAA-400, Ingos, Prague, Czech Republic). Ten chicken hearts were thereafter injected with $50 \mu \mathrm{L}$ doxorubicin dissolved in physiological saline solution to the final concentration of $1000 \mu \mathrm{g} \mathrm{mL}{ }^{-1}$. For confirmation of the presence of DOX in the myocardium, a Carestream In Vivo Xtreme Imaging System (Carestream Health, Inc., Rochester, NY, USA) was used to detect the fluorescence of doxorubicin after one hour-lasting exposure. Parameters were set as it follows: excitation wavelength $-480 \mathrm{~nm}$, emission wavelength $-600 \mathrm{~nm}$, exposure time $-2 \mathrm{~s}$, binning $-2 \times 2, f$-stop -1.1 , field of view $-7.2 \times 7.2 \mathrm{~cm}$. For analysis of amino acids profile in myocardium, samples were prepared in the same way as was described above in this chapter. Analysis was then carried out at on an analyzer of amino acids (Model AAA-400, Ingos, Prague, Czech Republic) using conditions described in chapter "Determination of content of amino acids in myocardium and analysis of interactions using IELC'. To compare content of amino acids before and after application of DOX, the differences were expressed as percentage disparities.

\subsection{Preparation of Amino Acid-Doxorubicin Sample for Interaction Study}

The results showing the most abundant amino acids in chicken hearts were further used to monitor interactions with DOX. The stock solutions of amino acids (AA) and doxorubicin were prepared daily in the concentration of $1 \mathrm{mg} \mathrm{mL}^{-1}$ by diluting with ACS water. The final concentrations of AA and DOX were prepared by diluting with ACS water from the stock solutions unless noted otherwise. The concentrations of DOX of $8 ; 16 ; 32 ; 64 ; 125 ; 250 ; 500$ and $1000 \mu \mathrm{g} \mathrm{mL}^{-1}$ interacting with the constant concentration of amino acids of $100 \mu \mathrm{g} \mathrm{mL}^{-1}$ were used for IELC evaluation of AA-DOX interactions. The concentrations of individual amino acids of $1 ; 2 ; 3 ; 6 ; 12 ; 25 ; 50$ and $100 \mu \mathrm{mol} \mathrm{mL}^{-1}$ were used to obtain absorption spectra of AA-DOX interactions. The absorption spectra were obtained after $24 \mathrm{~h}$ of interaction at $25{ }^{\circ} \mathrm{C}$ with doxorubicin in concentration of $250 \mu \mathrm{g} \mathrm{mL}$. 


\subsection{Determination of Content of Amino Acids in Myocardium and Analysis of Interactions Using IELC}

Firstly, IELC was used to determine AA content in myocardium before and after DOX application. An ion-exchange liquid chromatography (Model AAA-400, Ingos, Prague, Czech Republic) with post column derivatization by ninhydrin and an absorbance detector in the visible light range (VIS) was used. A glass column with inner diameter of $3.7 \mathrm{~mm}$ and $350 \mathrm{~mm}$ length was filled manually with strong cation exchanger in the sodium cycle LG ANB with approximately $12 \mu \mathrm{m}$ particles and $8 \%$ porosity. The column was tempered on the $60{ }^{\circ} \mathrm{C}$. The double channel VIS detector with an inner cell of $5 \mu \mathrm{L}$ volume was set to two wavelengths: 440 and $570 \mathrm{~nm}$. Solution of ninhydrin was prepared in $75 \%$ v/v methylcelosolve (Ingos, Prague, Czech Republic) and in 2\% v/v $4 \mathrm{M}$ acetic buffer (pH 5.5). Tin chloride $\left(\mathrm{SnCl}_{2}\right)$ was used as a reducing agent. Prepared solution of ninhydrin was stored under inert atmosphere $\left(\mathrm{N}_{2}\right)$ in dark at $4{ }^{\circ} \mathrm{C}$. Elution of amino acid was done by a buffer containing $10.0 \mathrm{~g}$ of citric acid, $5.6 \mathrm{~g}$ of sodium citrate, and $8.36 \mathrm{~g}$ of $\mathrm{NaCl}$ per liter of solution and $\mathrm{pH}$ was 3.0. Flow rate was $0.25 \mathrm{~mL} \mathrm{~min}^{-1}$. Reactor temperature was set on $120{ }^{\circ} \mathrm{C}$. For dilution of samples, a dilution buffer was used (composition: thiodiglycol $5 \mathrm{~mL} \mathrm{~L}^{-1}$, citric acid $14 \mathrm{~g} \mathrm{~L}^{-1}$, sodium chloride $11.5 \mathrm{~g} \mathrm{~mL}^{-1}$ ). For monitoring of AA-DOX interactions the same parameters of analysis were used instead of the time of analysis, which depended on amino acid determined.

\subsection{Spectrophotometric Analysis}

Absorption spectra of interactions between amino acids and doxorubicin were carried out on a spectrophotometer SPECORD 210 (Analytik Jena AG, Jena, Germany) within the range from 220 to $800 \mathrm{~nm}$ with $1 \mathrm{~nm}$ step. For analysis, an UV semi-micro plastic cuvette with $1 \mathrm{~cm}$ optical path (Brand GMBH, Wertheim, Germany) was used. Cell compartment was thermostated to $25^{\circ} \mathrm{C}$ by a thermostat Julabo (Labortechnik, Wasserburg, Germany). Absorption spectra were recorded after $24 \mathrm{~h}$ of the interaction and evaluated by the program WinASPECT version 2.2.7.0 (Analytik Jena AG, Jena, Germany). Finally, differential spectra of DOX-AA interactions were processed according to the formula:

$$
\text { spectrum }_{\text {DOX-AA }}-\text { spectrum }_{\text {DOX }}
$$

\subsection{Determination of Breaking Points of Amino Acids}

For the function calculating the breaking points of amino acids, following variables were defined: $a$ for absorbance ( $y$-axis), $l$ for lowest point on $y$-axis, $u$ for uppermost point on $y$-axis, $k$ for slope of curve, $i$ for $\log$ breakpoint position and $c$ for concentration of doxorubicin. Using these variables, the relation of doxorubicin concentration and absorbance can be expressed as it follows:

$$
a=l-\frac{u-l}{1+10^{k(i-c)}}
$$

To fit the curve, variables $l, u, k$ and $i$ were calculated using the least squares method. Consequently, breakpoint $(b)$ was subsequently calculated according to:

$$
b=10^{i}
$$


Macro in Microsoft Excel using a solver tool was used to create the fit of the curve and to calculate the breaking points of individual amino acids.

\subsection{Descriptive Statistics}

Mathematical analyses of the experimental data and their graphical interpretation were realized by the Microsoft Office tools (MS Excel ${ }^{\circledR}$, MS Word ${ }^{\circledR}$, and MS PowerPoint ${ }^{\circledR}$ ). All results were expressed as a mean \pm standard deviation (S.D.) unless noted otherwise. The detection limits (3 signal/noise, $\mathrm{S} / \mathrm{N}$ ) were calculated according to Long and Winefordner [55], whereas $\mathrm{N}$ was expressed as a standard deviation of noise determined in the signal domain unless stated otherwise. Differences with $p<0.05$ were considered significant and were determined by using of one way ANOVA test (particularly Scheffe test), which was applied for means comparison.

\section{Conclusions}

In our study, we determined that doxorubicin induces formation of complexes with amino acids in myocardium. This fact supports the well-known knowledge about the cardiotoxicity of doxorubicin. Despite the fact that some hypotheses about the mechanism of the anthracycline-induced cardiotoxicity have been established, it has not yet been sufficiently explained. An effect of doxorubicin on amino acids may be an important factor involved in this multifactorial and very complicated process. Possible formations of complexes may play important role in the adverse effects of doxorubicin; however, this phenomenon must be further investigated. We also carried out comparison of the quantitative representation of amino acids in myocardium before and after application of doxorubicin. We observed significant reduction of levels of all amino acids in myocardium after exposure to doxorubicin. These findings lead us to knowledge that amino acids play an important role in the cardiotoxicity of doxorubicin in a dose-dependent manner. Initial amino acid composition of heart may hypothetically play an essential role in resistance of heart to doxorubicin. Nevertheless, sensitive BCAAs are very much needed for mTOR managed proteosynthesis. The solution might be found in nutrition supplements providing branched chain amino acids, and thus protecting the proper function of protein synthesis, but their effectiveness would have to be tested. It is important to reveal if DOX induced damage leads to alterations of contractility or cardiac conduction and if there is any chance how to recognize the progressive and reversible damage. From these purposes we have the future plans to carry out in vivo experiments, further uncovering this phenomenon. Understanding the pathophysiology of cardiac dysfunction associated with anthracyclines is important for prediction, treatment, and prevention of these adverse side effects of chemotherapy.

\section{Acknowledgments}

Financial support from CYTORES GACR P301/10/0356, CEITEC CZ.1.05/1.1.00/02.0068, by MH CZ-DRO, University Hospital Motol, Prague, Czech Republic 00064203 and Liga proti rakovine LPR 2014 is highly acknowledged. 


\section{Conflicts of Interest}

The authors declare no conflict of interest.

\section{References}

1. Das, J.; Ghosh, J.; Manna, P.; Sil, P.C. Taurine protects rat testes against doxorubicin-induced oxidative stress as well as p53, Fas and caspase 12-mediated apoptosis. Amino Acids 2012, 42, 1839-1855.

2. Holley, A.K.; Dhar, S.K.; Xu, Y.; St Clair, D.K. Manganese superoxide dismutase: Beyond life and death. Amino Acids 2012, 42, 139-158.

3. Hossain, S.; Yamamoto, H.; Chowdhury, E.H.; Wu, X.; Hirose, H.; Haque, A.; Doki, Y.; Mori, M.; Akaike, T. Fabrication and intracellular delivery of doxorubicin/carbonate apatite nanocomposites: Effect on growth retardation of established colon tumor. PLoS One 2013, 8, 1-11.

4. Farolfi, A.; Melegari, E.; Aquilina, M.; Scarpi, E.; Ibrahim, T.; Maltoni, R.; Sarti, S.; Cecconetto, L.; Pietri, E.; Ferrario, C.; et al. Trastuzumab-induced cardiotoxicity in early breast cancer patients: A retrospective study of possible risk and protective factors. Heart 2013, 99, 634-639.

5. Li, M.Q.; Song, W.T.; Tang, Z.H.; Lv, S.X.; Lin, L.; Sun, H.; Li, Q.S.; Yang, Y.; Hong, H.; Chen, X.S. Nanoscaled poly(L-glutamic acid)/doxorubicin-amphiphile complex as pH-responsive drug delivery system for effective treatment of nonsmall cell lung cancer. ACS Appl. Mater. Interfaces 2013, 5, 1781-1792.

6. Nissen, M.J.; Tsai, M.L.; Blaes, A.H.; Swenson, K.K.; Koering, S. Effectiveness of treatment summaries in increasing breast and colorectal cancer survivors' knowledge about their diagnosis and treatment. J. Cancer Surviv. 2013, 7, 211-218.

7. Minotti, G.; Menna, P.; Salvatorelli, E.; Cairo, G.; Gianni, L. Anthracyclines: Molecular advances and pharmacologic developments in antitumor activity and cardiotoxicity. Pharmacol. Rev. 2004, 56, 185-229.

8. Yuan, A.; Wu, J.H.; Song, C.C.; Tang, X.L.; Qiao, Q.; Zhao, L.L.; Gong, G.M.; Hu, Y.Q. A novel self-assembly albumin nanocarrier for reducing doxorubicin-mediated cardiotoxicity. J. Pharm. Sci. 2013, 102, 1626-1635.

9. Box, V.G.S. The intercalation of DNA double helices with doxorubicin and nagalomycin. J. Mol. Gr. Model. 2007, 26, 14-19.

10. Swift, L.P.; Rephaeli, A.; Nudelman, A.; Phillips, D.R.; Cutts, S.M. Doxorubicin-DNA adducts induce a non-topoisomerase II-mediated form of cell death. Cancer Res. 2006, 66, 4863-4871.

11. Schwartz, R.G.; Jain, D.; Storozynsky, E. Traditional and novel methods to assess and prevent chemotherapy-related cardiac dysfunction noninvasively. J. Nuclear Cardiol. 2013, 20, 443-464.

12. Kizek, R.; Adam, V.; Hrabeta, J.; Eckschlager, T.; Smutny, S.; Burda, J.V.; Frei, E.; Stiborova, M. Anthracyclines and ellipticines as DNA-damaging anticancer drugs: Recent advances. Pharmacol. Ther. 2012, 133, 26-39.

13. Perego, P.; Corna, E.; de Cesare, M.; Gatti, L.; Polizzi, D.; Pratesi, G.; Supino, R.; Zunino, F. Role of apoptosis and apoptosis-related genes in cellular response and antitumor efficacy of anthracyclines. Curr. Med. Chem. 2001, 8, 31-37. 
14. Yang, E.S.; Huh, Y.J.; Park, J.W. RNA interference targeting sensitive-to-apoptosis gene potentiates doxorubicin- and staurosporine-induced apoptosis of PC3 cells. Anticancer Res. 2013, 33, 847-855.

15. Wallace, K.B. Doxorubicin-induced cardiac mitochondrionopathy. Pharm. Toxicol. 2003, 93, 105-115.

16. Sardao, V.A.; Oliveira, P.J.; Holy, J.; Oliveira, C.R.; Wallace, K.B. Doxorubicin-induced mitochondrial dysfunction is secondary to nuclear p53 activation in H9c2 cardiomyoblasts. Cancer Chemother. Pharm. 2009, 64, 811-827.

17. Toldo, S.; Goehe, R.W.; Lotrionte, M.; Mezzaroma, E.; Sumner, E.T.; Biondi-Zoccai, G.G.L.; Seropian, I.M.; van Tassell, B.W.; Loperfido, F.; Palazzoni, G.; et al. Comparative cardiac toxicity of anthracyclines in vitro and in vivo in the mouse. PLoS One 2013, 8, 1-8.

18. Fong, M.Y.; Jin, S.Y.; Rane, M.; Singh, R.K.; Gupta, R.; Kakar, S.S. Withaferin a synergizes the therapeutic effect of doxorubicin through ROS-mediated autophagy in ovarian cancer. PLoS One 2012, 7, 1-16.

19. Gharanei, M.; Hussain, A.; Janneh, O.; Maddock, H.L. Doxorubicin induced myocardial injury is exacerbated following ischaemic stress via opening of the mitochondrial permeability transition pore. Toxicol. Appl. Pharm. 2013, 268, 149-156.

20. Yang, J.Q.; Maity, B.; Huang, J.; Gao, Z.; Stewart, A.; Weiss, R.M.; Anderson, M.E.; Fisher, R.A. G-protein inactivator RGS6 mediates myocardial cell apoptosis and cardiomyopathy caused by doxorubicin. Cancer Res. 2013, 73, 1662-1667.

21. Yao, Z.W.; Hu, W.; Yin, S.; Huang, Z.; Zhu, Q.; Chen, J.N.; Zang, Y.H.; Dong, L.; Zhang, J.F. 3,3'-Diindolymethane ameliorates adriamycin-induced cardiac fibrosis via activation of a BRCA1-dependent anti-oxidant pathway. Pharm. Res. 2013, 70, 139-146.

22. Zeng, Q.B.; Wen, H.B.; Wen, Q.; Chen, X.H.; Wang, Y.G.; Xuan, W.L.; Liang, J.S.; Wan, S.H. Cucumber mosaic virus as drug delivery vehicle for doxorubicin. Biomaterials 2013, 34, 4632-4642.

23. Eckman, D.M.; Stacey, R.B.; Rowe, R.; D’Agostino, R.; Kock, N.D.; Sane, D.C.; Torti, F.M.; Yeboah, J.; Workman, S.; Lane, K.S.; et al. Weekly doxorubicin increases coronary arteriolar wall and adventitial thickness. PLoS One 2013, 8, 1-6.

24. Pereira Neto, G.B.; Andrade, J.N.B.; Sousa, M.G.; Camacho, A.A. Holter electrocardiography in dogs showing doxorubicin-induced dilated cardiomyopathy. Arq. Bras. Med. Vet. Zootec. 2006, $58,1037-1042$.

25. Lim, C.C.; Zuppinger, C.; Guo, X.X.; Kuster, G.M.; Helmes, M.; Eppenberger, H.M.; Suter, T.M.; Liao, R.L.; Sawyer, D.B. Anthracyclines induce calpain-dependent titin proteolysis and necrosis in cardiomyocytes. J. Biol. Chem. 2004, 279, 8290-8299.

26. Liu, T.C.K.; Ismail, S.; Brennan, O.; Hastings, C.; Duffy, G.P. Encapsulation of cardiac stem cells in superoxide dismutase-loaded alginate prevents doxorubicin-mediated toxicity. J. Tissue Eng. Regen. Med. 2013, 7, 302-311.

27. Masarik, M.; Kynclova, H.; Huska, D.; Hubalek, J.; Adam, V.; Babula, P.; Eckschlager, T.; Stiborova, M.; Kizek, R. DNA-doxorubicin interactions revealed by electrochemistry. Int. J. Mol. Med. 2010, 26, 46. 
28. Feridooni, T.; Hotchkiss, A.; Remley-Carr, S.; Saga, Y.; Pasumarthi, K.B.S. Cardiomyocyte specific ablation of p53 is not sufficient to block doxorubicin induced cardiac fibrosis and associated cytoskeletal changes. PLoS One 2011, 6, 1-12.

29. Drake, K.J.; Sidorov, V.Y.; McGuinness, O.P.; Wasserman, D.H.; Wikswo, J.P. Amino acids as metabolic substrates during cardiac ischemia. Exp. Biol. Med. 2012, 237, 1369-1378.

30. Nejdl, L.; Sochor, J.; Zitka, O.; Cernei, N.; Ruttkay-Nedecky, B.; Kopel, P.; Babula, P.; Adam, V.; Hubalek, J.; Kizek, R. Spectrometric and chromatographic study of reactive oxidants hypochlorous and hypobromous acids and their interactions with taurine. Chromatographia 2013, 76, 363-373.

31. Huang, Y.; Zhou, M.Y.; Sun, H.P.; Wang, Y.B. Branched-chain amino acid metabolism in heart disease: An epiphenomenon or a real culprit? Cardiovasc. Res. 2011, 90, 220-223.

32. Weitzel, L.B.; Ambardekar, A.V.; Brieke, A.; Cleveland, J.C.; Serkova, N.J.; Wischmeyer, P.E.; Lowes, B.D. Left ventricular assist device effects on metabolic substrates in the failing heart. PLoS One 2013, 8, 1-6.

33. Tazina, E.V.; Ignatieva, E.V.; Polozkova, A.P.; Oborotova, N.A. Qualitative and quantitative analysis of thermosensitive liposomes loaded with doxorubicin. Pharm. Chem. J. 2012, 46, 54-59.

34. Albright, C.F.; Graciani, N.; Han, W.; Yue, E.; Stein, R.; Lai, Z.H.; Diamond, M.; Dowling, R.; Grimminger, L.; Zhang, S.Y.; et al. Matrix metalloproteinase-activated doxorubicin prodrugs inhibit HT1080 xenograft growth doxorubicin with less toxicity. Mol. Cancer Ther. 2005, 4, 751-760.

35. Manocha, B.; Margaritis, A. Controlled release of doxorubicin from doxorubicin $/ \gamma$-polyglutamic acid ionic complex. J. Nanomater. 2010, 2010, 1-9.

36. Taetrneyer, H.; Harinstein, M.E.; Gheorghiade, M. More than bricks and mortar: Comments on protein and amino acid metabolism in the heart. Am. J. Cardiol. 2008, 101, 3E-7E.

37. Proud, C.G. Regulation of mammalian translation factors by nutrients. Eur. J. Biochem. 2002, 269, 5338-5349.

38. Zhang, D.H.; Contu, R.; Latronico, M.V.G.; Zhang, J.A.L.; Rizzi, R.; Catalucci, D.; Miyamoto, S.; Huang, K.; Ceci, M.; Gu, Y.S.; et al. MTORC1 regulates cardiac function and myocyte survival through 4E-BP1 inhibition in mice. J. Clin. Investig. 2010, 120, 2805-2816.

39. Katta, A.; Kundla, S.; Kakarla, S.K.; Wu, M.Z.; Fannin, J.; Paturi, S.; Liu, H.; Addagarla, H.S.; Blough, E.R. Impaired overload-induced hypertrophy is associated with diminished mTOR signaling in insulin-resistant skeletal muscle of the obese Zucker rat. Am. J. Physiol. Regul. Integr. Comp. Physiol. 2010, 299, R1666-R1675.

40. Wullschleger, S.; Loewith, R.; Hall, M.N. TOR signaling in growth and metabolism. Cell 2006, 124, 471-484.

41. Porstmann, T.; Santos, C.R.; Griffiths, B.; Cully, M.; Wu, M.; Leevers, S.; Griffiths, J.R.; Chung, Y.L.; Schulze, A. SREBP activity is regulated by mTORC1 and contributes to Akt-dependent cell growth. Cell Metab. 2008, 8, 224-236.

42. Zima, T.; Tesar, V.; Mantle, D.; Koll, M.; Patel, V.; Richardson, P.J.; Preedy, V.R. Acute doxorubicin (adriamycin) dosage does not reduce cardiac protein synthesis in vivo, but decreases diaminopeptidase I and proline endopeptidase activities. Exp. Mol. Pathol. 2001, $70,154-161$.

43. Takemura, G.; Fujiwara, H. Doxorubicin-induccd cardiomyopathy from the cardiotoxic mechanisms to management. Prog. Cardiovasc. Dis. 2007, 49, 330-352. 
44. Gianni, L.; Herman, E.H.; Lipshultz, S.E.; Minotti, G.; Sarvazyan, N.; Sawyer, D.B. Anthracycline cardiotoxicity: From bench to bedside. J. Clin. Oncol. 2008, 26, 3777-3784.

45. Yellon, D.M.; Hausenloy, D.J. Mechanisms of disease: Myocardial reperfusion injury. N. Engl. J. Med. 2007, 357, 1121-1135.

46. Halestrap, A.P. What is the mitochondrial permeability transition pore? J. Mol. Cell. Cardiol. 2009, 46, 821-831.

47. Halestrap, A.P.; Pasdois, P. The role of the mitochondrial permeability transition pore in heart disease. Biochim. Biophys. Acta 2009, 1787, 1402-1415.

48. Gava, F.N.; Zacche, E.; Ortiz, E.M.G.; Champion, T.; Bandarra, M.B.; Vasconcelos, R.O.; Barbosa, J.C.; Camacho, A.A. Doxorubicin induced dilated cardiomyopathy in a rabbit model: An update. Res. Vet. Sci. 2013, 94, 115-121.

49. She, P.X.; Olson, K.C.; Kadota, Y.; Inukai, A.; Shimomura, Y.; Hoppel, C.L.; Adams, S.H.; Kawamata, Y.; Matsumoto, H.; Sakai, R.; et al. Leucine and protein metabolism in obese zucker rats. PLoS One 2013, 8, 1-19.

50. Wilkinson, D.J.; Hossain, T.; Hill, D.S.; Phillips, B.E.; Crossland, H.; Williams, J.; Loughna, P.; Churchward-Venne, T.A.; Breen, L.; Phillips, S.M.; et al. Effects of leucine and its metabolite $\beta$-hydroxy- $\beta$-methylbutyrate on human skeletal muscle protein metabolism. J. Physiol. 2013, 591, 2911-2923.

51. Yoo, H.S.; Park, T.G. Folate-receptor-targeted delivery of doxorubicin nano-aggregates stabilized by doxorubicin-PEG-folate conjugate. J. Control. Release 2004, 100, 247-256.

52. Ryppa, C.; Mann-Steinberg, H.; Fichtner, I.; Weber, H.; Satchi-Fainaro, R.; Biniossek, M.L.; Kratz, F. In vitro and in vivo evaluation of doxorubicin conjugates with the divalent peptide E- $\left[\mathrm{c}(\mathrm{RGDfK})_{2}\right]$ that targets integrin $\alpha_{\mathrm{v}} \beta_{3}$. Bioconjug. Chem. 2008, 19, 1414-1422.

53. King, H.D.; Dubowchik, G.M.; Mastalerz, H.; Willner, D.; Hofstead, S.J.; Firestone, R.A.; Lasch, S.J.; Trail, P.A. Monoclonal antibody conjugates of doxorubicin prepared with branched peptide linkers: Inhibition of aggregation by methoxytriethyleneglycol chains. J. Med. Chem. 2002, 45, 4336-4343.

54. Agudelo, D.; Bourassa, P.; Bruneau, J.; Berube, G.; Asselin, E.; Tajmir-Riahi, H.A. Probing the binding sites of antibiotic drugs doxorubicin and $\mathrm{N}$-(trifluoroacetyl) doxorubicin with human and bovine serum albumins. PLoS One 2012, 7, 1-13.

55. Long, G.L.; Winefordner, J.D. Limit of detection. Anal. Chem. 1983, 55, A712-A724.

(C) 2013 by the authors; licensee MDPI, Basel, Switzerland. This article is an open access article distributed under the terms and conditions of the Creative Commons Attribution license (http://creativecommons.org/licenses/by/3.0/). 